\title{
Journal: Journal of Marriage and Family
}

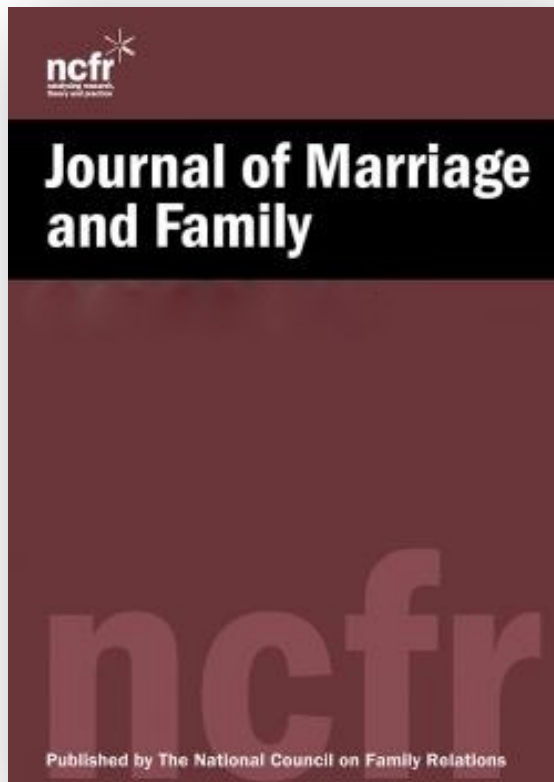

Link to Paper:

http://onlinelibrary.wiley.com/doi/10.1111/jomf.12225/abstract 


\title{
Gender and Children's Housework Time in China: Examining Behavior Modeling in Context
}

\section{Yang Hu}

\begin{abstract}
Differentiated gender roles in adulthood are rooted in one's gender role socialization. In order to understand the persistence of gender inequalities in the domestic sphere, we need to examine the gendered patterns of children's housework time. Although researchers have identified behavior modeling as a major mechanism of gender role reproduction and characterized gender socialization as a contextually embedded process, few have investigated contextual variation in behavior modeling, particularly in non-Western developing countries. Analyzing data from the China Family Panel Studies 2010, the author examined the differences in behavior modeling between boys and girls age 10-15 from 2-parent families ( $N$ $=1,903$ ) in rural and urban China. The results revealed distinctive gendered interplays in the way parental housework and employment behavior helps shape children's housework time. This analysis is a crucial illustration of how the distinctive sociocultural contexts of rural and urban China moderate the effects of housework-behavior modeling on intergenerational gender role socialization.
\end{abstract}


In the past few decades, despite a rise in women's paid employment, women in both China and the West continue to shoulder the lion's share of housework (Bittman, England, Sayer, Folbre, \& Matheson, 2003; Gershuny, 2003; Yu, 2014). Although this gender gap has usually been addressed in relation to adults' housework activities (e.g., Bittman et al., 2003; Gershuny, 2004; Yu, 2014), such gendered patterns can be traced back to differentiated socialization during childhood (Goffman, 1977; Raley \& Bianchi, 2006). Researchers in countries such as the United States (Blair, 1992; Manke, Seery, Crouter, \& McHale, 1994), Sweden (Evertsson, 2006), and Spain (Álvarez \& Miles-Touya, 2012) have found that girls spend twice as much time as boys on housework, mirroring their adult counterparts. Given that the influence of early formations of gender identity, preferences, and behavior may persist in later life (Lundberg, 2005), it is important to examine the gendered socialization of children's housework behavior as a mechanism for the (re)production of gender inequalities.

Family matters as a "gender depot" (Goffman, 1977). In contemporary China, despite the strict enforcement of gender egalitarianism in the public sphere (Evans \& Strauss, 2011), family remains a major site in which differentiated gender roles are reproduced (Zuo \& Bian, 2001). Previous research has identified behavior modeling - children's imitation of parents' housework and employment behavior - as a key mechanism of gender role reproduction (Cunningham, 2001a, 2001b), a fact that underlines the importance of intergenerational relationships between parents and children (Gupta, 2006; Raley \& Bianchi, 2006).

Despite its significant influence on children's gender roles, the institution of family does not operate alone (Greenstein, 1996). As Cunningham (2001b) noted, behavior modeling theorists have usually isolated intergenerational processes as an independent entity of analysis and thus have paid insufficient attention to the specific sociocultural contexts in which family is embedded. The importance of sociocultural context to gender role socialization has been emphasized by those who conceptualize gender as a situated performance (West \& Zimmerman, 1987) and those who regard socialization as a contextually embedded process, following Bronfenbrenner's (1989) ecological systems theory. Furthermore, gender norms and resources such as domestic-outsourcing options also vary considerably across social settings. Such contextual variability, according to McHale, Crouter, and Whiteman (2003), underpins inconsistent past findings on the gendered patterns of children's housework. Therefore, there is a need to compare the distinct patterns of behavior modeling in varying social contexts.

Why should we focus on China? To date, the housework activities of Chinese children remains an understudied topic. Because previous research has been conducted mostly in what Lundberg (2005, p. 340) referred to as "wealthy, non-traditional Western" societies, it is important to examine whether the intergenerational modeling of gendered housework and 
employment behavior occurs similarly or differently in developed and developing societies. Defined for centuries by patriarchal traditions, Chinese society has undergone drastic changes in the past several decades. However, the uneven reach of recent social policies, events, and other developments has created a vast divide between rural and urban China (Whyte, 2010). The homogeneous sociocultural origin and rural-urban divergence make China a potentially fruitful setting in which to examine behavior modeling in varying and comparable social contexts.

Using data from the 2010 China Family Panel Studies (CFPS; http://www.isss.edu.cn/cfps/ $\mathrm{EN} /$ ) on children age 10-15 from two-parent, coresiding families, I investigated the relationship between the parents' relative share of housework time and children's housework time in the Chinese context, in particular how China's rural and urban contexts moderate the effects of behavior modeling on intergenerational gender role socialization. I limited the focus to families with two coresiding parents because my primary aim was to address the influence and interplay of the gender roles of mothers and fathers on their male and female children.

\section{Background}

\section{Study Setting: China-One Country, Two Societies}

In feudal and imperial China, family and gender relations were heavily influenced by patriarchal and patrilineal traditions. As in most preindustrial societies, men monopolized productive activities, and women were responsible for domestic activities and reproduction (Whyte, 1978). After 1949, socialist revolutions overturned "feudal remnants" and mobilized women into the labor market. After 1978 economic reform, however, the Communist Party no longer enforced gender egalitarianism "from top-down" (Evans \& Strauss, 2011). Social processes such as urbanization, the open-door policy, and the one-child policy have since had various effects on gender role attitudes and behaviors in China. Because of the uneven spread of these policies, China's domestic and public spheres and rural and urban areas have diverged in their development, leading to what Whyte (2010) called "one country, two societies."

The divide between the domestic and public spheres could be partially ascribed to the incomplete gender revolution led by the Communist Party. According to Whyte (1978) and Zuo and Bian (2001), women's labor force participation was not internally driven but externally motivated by the party's gender-equality rhetoric in the socialist era. The legacies 
of China's socialist revolutions persist to this date in the public sphere. In the post-reform era, the rate of women's labor force participation in rural areas has remained consistently above 85\%, compared with $90 \%$ for men (Organisation for Economic Cooperation and Development [OECD], 2015). In 2010, 65\% of urban women and $77 \%$ of urban men participated in the labor force (OECD, 2015); the former is higher than that in most OECD countries. In 2011, 51.2\% of university students were female (OECD, 2011) and, in this respect, China is similar to the majority of OECD nations where women now outnumber men in higher education. Despite the progress made toward gender equality in the public sphere, gender inequality persists in the domestic sphere. Although Hu and Scott (2014) found that paid employment erodes traditional gender role values among post-reform women, $\mathrm{Yu}$ (2014) found that Chinese women still spend twice as much time as men on housework.

At a societal level, there are considerable rural-urban differences in terms of gendered domesticity. First, following the 1978 open-door policy, urban centers were prioritized for international trade and commerce, which promulgated feminist ideas in urban, but not rural, areas (Evans \& Strauss, 2011; Yan, 2009). Second, China's partial industrialization enabled domestic outsourcing and labor-saving tools for urban, but not rural, Chinese (Whyte, 2010). Third, the one-child policy has been more closely observed in urban than in rural areas, and women with only one child are liberated from domesticity to a greater degree than those with multiple children (Greenhalgh, 2008). Fourth, whereas Fong (2002) found educational resources and opportunities to be equalized for boys and girls in urban areas, Greenhalgh (2008) indicated that education is prioritized for boys over girls in rural areas. As a result, urban Chinese hold more egalitarian gender role attitudes toward domesticity than their rural counterparts.

In what West and Zimmerman (1987, p. 126) referred to as a "situated doing," the nature of gendered housework is contingent on social context. In Western studies, the gendered division of housework has often been framed as the specialization of sex-typed "outdoor" and "indoor" chores (Becker, 1991). However, outdoor chores (e.g., gardening) do not apply to most urban Chinese families living in apartments. In agricultural rural areas, parents' outdoor activities are usually associated with paid labor (Tam, Wong, \& Wang, 2014). Instead, the degree of male and female participation in housework rather than gender specialization could be more telling about gendered domestic patterns in China. Therefore, in this research I focused on the time spent by children and their parents on housework. I paid particular attention to the relative time spent by mothers and fathers on housework, given that gender roles are enacted in relative terms (Raley \& Bianchi, 2006). In the ensuing sections I use the phrase "father's relative share of the parents' housework time," which is derived as a percentage of the total housework time of fathers and mothers combined. 


\section{Theoretical Framework and Hypotheses: Gender and Children's}

\section{Housework Time}

Children gain their first, and long-lasting, impressions of how gendered lives can or should be organized from exposure to and interaction with their parents (Cunningham, 2001a). From observation of the gendered behavior of their parents, children learn that certain behavior can be construed as defining their own gender identity (Greenstein, 1996; Lundberg, 2005). According to behavior modeling theory, which is rooted in social learning theory (Bandura \& Walters, 1963), boys and girls imitate the behavior of their parents, who function as role models (Grusec \& Hastings, 2008). To be specific, researchers have distinguished between parents' housework behavior at home and their employment behavior at work (Crouter, McHale, \& Bartko, 1993; Gupta, 2006).

On the one hand, children may emulate their parents' housework performance directly (Cunningham, 2001a). On the other hand, parents tend to assign more housework to girls than to boys (Andersson, Hank, Rønsen, \& Vikat, 2006; Bianchi \& Robinson, 1997), and such assignments are often sex typed (Blair, 1992). However, even when delegating domestic tasks to children, parents usually reproduce and reinforce the norms that shaped their own gendered housework behavior (Álvarez \& Miles-Touya, 2012). Of note is that houseworkbehavior modeling is particularly salient between parents and children of the same gender (McHale, Bartko, Crouter, \& Perry-Jenkins, 1990), and it varies significantly with children's gender (Álvarez \& Miles-Touya, 2012; Evertsson, 2006; McHale et al., 2003).

For boys, past research has consistently supported housework-behavior modeling, showing that a son's housework time increases with his father's relative share of housework (e.g., Cunningham, 2001a; Evertsson, 2006), as he imitates his father's housework behavior or participates in joint housework activities with his father. For girls, housework-behavior modeling would predict that a daughter's housework time would be positively associated with her mother's relative share of housework (i.e., negatively associated with the father's relative share of housework), as she imitates or partakes in her mother's housework activities. Nevertheless, new home economists have argued the opposite: Their substitution theory indicates that daughters are more likely than sons to act as "natural substitutes" by compensating for mothers' decreased share of housework time (Benin \& Edwards, 1990; Coltrane, 2000; Goldscheider \& Waite, 1991; Gupta, 2006; Lundberg, 2005), especially in societies such as China, where females are largely expected to undertake housework (Evans, 2008). Daughters may model their mothers' increased or decreased housework undertaking, but at the same time they may substitute for their mothers' absence from housework to a lesser or greater degree. Therefore, the influences of housework-behavior modeling and 
substitution on daughters may offset each other; Cunningham (2001b), Evertsson (2006), and Manke et al. (1994) have consistently found that daughters' housework time is unlikely to be affected by the parents' relative share of housework time.

Hypothesis 1: Fathers' relative share of the parents' housework time is positively associated with sons' housework time, but it is not significantly associated with daughters' housework time.

On the other hand, parents' employment behavior provides children with a model of gender roles in the public sphere (Grusec \& Hastings, 2008). Paid employment increases women's relative resources and erodes traditional gender role values in Western (Bittman et al., 2003) and Chinese societies alike (Hu \& Scott, 2014). Maternal employment can have a direct behavioral impact on daughters' employment in the long run, once they leave school. However, maternal employment indirectly fosters higher educational aspiration (Raley \& Bianchi, 2006) and egalitarian gender role values among daughters, but not among sons (Fong, 2002; McHale et al., 2003). Nonetheless, if daughters' egalitarian gender role values (as a result of maternal employment) lead to a decrease in their housework time, such an effect may be offset by an increased demand for daughters' substitution in dual-earner compared to male-breadwinner families (Benin \& Edwards, 1990; Coltrane, 2000;

Goldscheider \& Waite, 1991). Therefore, although researchers such as Cunningham (2001a, 2001b) have found that early maternal employment leads to female children's egalitarian gender roles on entering adulthood, parents' employment behavior may not affect younger girls' housework time.

In contrast, fathers have been observed to respond to their wives' employment by doing more housework (Bittman et al., 2003; Yu, 2014), which is particularly true for families with no daughter (Benin \& Edwards, 1990). This change in fathers' housework behavior caused by maternal employment is mirrored, in turn, by an increase in sons' housework time in dualearner compared with male-breadwinner families through father-son housework-behavior modeling (Benin \& Edwards, 1990; Gupta, 2006).

Hypothesis 2: Sons spend more time on housework in dual-earner than malebreadwinner families, but daughters' housework time is not significantly associated with family earning type.

Parents' housework and employment behavior do not operate independently. Crouter, PerryJenkins, Huston, and McHale (1987) found the father's housework behavior in malebreadwinner families to be "discretionary" and thus largely determined by his gender role attitudes. The same observation may apply to male-breadwinner Chinese families in which gender role values remain relatively traditional (Hu \& Scott, 2014) and men only "chip in" 
for domestic labor (Yu, 2014). In dual-earner families sons are more likely to contribute to housework when help is needed (Benin \& Edwards, 1990); their housework behavior is influenced less by their parents' housework behavior than by the family's needs (Crouter et al., 1987). This "discretionary" argument for how family earning type moderates houseworkbehavior modeling for sons is supported by studies conducted by McHale et al. (1990) and Álvarez and Miles-Touya (2012) that showed that fathers' housework behavior is significantly associated with sons' housework behavior in male-breadwinner, but not dualearner, families.

In contrast, for girls past research has consistently confirmed that the association between parents' relative share of housework time and daughters' housework time does not vary by family earning type (Evertsson, 2006; McHale et al., 1990). Benin and Edwards (1990) found that, in both male-breadwinner and dual-earner families, a mother's reduced share of the parents' housework may entail an increased demand for substitution from her daughter. Therefore, mothers' housework-behavior modeling and substitution may offset each other in their influence on daughters' housework in male-breadwinner and dual-earner families alike (Lundburg, 2005; Manke et al., 1994). Thus, family earning type does not moderate the association between the parents' relative share of housework and daughters' housework time.

Hypothesis 3: Fathers' relative share of the parents' housework time has a stronger positive association with sons' housework time in male-breadwinner than in dual-earner families; the association between fathers' relative share of housework time and daughters' housework time does not vary significantly by family earning type.

Because most previous research on children's housework has been conducted in developed, Western societies, McHale et al. (2003) underlined how little we know about whether and how housework-behavior modeling operates similarly or differently in distinct social contexts. Furthermore, boys and girls could relate to parental behavior and social context to varying degrees and in distinct ways. Despite a lack of systematic theorization and empirical investigation, researchers have offered two conjectures regarding how social context could moderate housework-behavior modeling differently for boys and girls.

On the one hand, for girls, Andersson et al. (2006) argued that parents' housework behavior may encourage or deter children from housework, depending on the (in)congruence of parents' behavior with sociocultural norms. Because norms of participation in housework are well defined for girls (McHale et al., 2003) and girls refer to social context when appraising their parents' gender roles (Crouter et al., 1993), they model their parents' housework behavior only when it is deemed congruent with contextual norms (Andersson et al., 2006). In China, an increase in the father's relative share of housework, and a decrease in that of the mother, is congruent to a greater degree in an urban context, where gender role values are 
more egalitarian, than in rural areas, where patriarchal norms hold sway. Meanwhile, according to the substitution theory, daughters would be allowed more discretion to model their parents' housework behavior when there are alternative substitution options such as domestic outsourcing and labor-saving appliances. Substitution options are more likely to be found in urban areas than in rural areas, where such options are limited (Benin \& Edwards, 1990; Coltrane, 2000; Gershuny, 2004; Goldscheider \& Waite, 1991).

Hypothesis 4A: In urban areas, with more alternative substitution options and more egalitarian gender role values, the strength of daughters' housework-behavior modeling is stronger than in rural areas, with fewer alternative substitution options and less egalitarian gender role values.

On the other hand, Crouter et al. (1993) and McHale et al. (2003) have noted that social norms for housework participation are less clearly defined for boys than for girls, and boys are more likely to take cues from their fathers (than from vaguely defined social norms) in learning to do housework. Although boys are less likely than girls to dwell on the existing values instilled by social context, Crouter et al. and Cunningham (2001b) have argued that fathers' housework behavior may help erode the cultural link between domesticity and femininity. According to their conjecture, because boys base their understanding of the acceptability of doing domestic chores on their fathers' behavior, fathers' increased share of the parents' housework time would reduce the normative association between housework and gender to a greater degree in social contexts of less egalitarian gender role values (Crouter et al., 1993; Cunningham, 2001b).

Hypothesis 4B: In rural areas, the strength of sons' housework-behavior modeling is stronger than in urban areas because the normative gender role values are less egalitarian in rural than in urban areas.

Because women's labor force participation is equally normalized in rural and urban China (Evans \& Strauss, 2011; Tam et al., 2014), there is no good reason to hypothesize a moderation effect of China's rural-urban context on employment-behavior modeling.

\section{Method}

\section{Data and Sample}

In this research, I used data from the child and adult panels of the CFPS, 2010 wave. Executed by the Institute of Social Science Survey at Peking University, the CFPS was 
conducted in collaboration with the Population Studies Center at the University of Michigan. Multi-stage probability-proportional-to-size sampling was used, with samples weighted in proportion to population structures at the administrative levels of county (or equivalent), village, and household. Sixteen thousand households from 25 provinces were surveyed, with a response rate of $81.28 \%$ at the household level.

The CFPS 2010 data are suited for the current study for two reasons. First, CFPS staff conducted individual face-to-face interviews with both child and adult members of the sampled households, thus yielding rich information on the time use of both parents and children. Second, the survey is representative of households from the eastern coast to the western hinterland, which allows representative comparisons to be drawn between rural and urban China.

To construct the analytical sample, I focused on two-parent families inclusive of children age 10-15 ( $M=12.49)$, with valid data on all key variables. The child panel of CFPS collected time use data only from children age 10-15. Because the primary aim of this research was to gauge the influence of mothers' and fathers' relative gender roles on their children, I excluded families in which either the mother or the father resided separately from their child(ren). This left 2,015 cases for further analysis. I then excluded 112 cases with missing data on key variables. No significant correlation was found between missing data and major demographic characteristics. The final analytical sample comprised 1,903 children, of which $49.2 \%$ were female, $76.8 \%$ were the only children resident in their respective households, and $58.9 \%$ were from rural areas. The mean age of the mothers was 38.23 , and that of the fathers was 39.85. See Table 1 for detailed sample characteristics.

\section{Dependent Variable: Children's Housework Time}

The children interviewed for the CPFS were asked how much time, on average, they spend on housework on a weekday and a weekend day, respectively, during school terms. Time was measured in tenths of an hour. The definition of housework in the CFPS includes chores such as cooking, housekeeping, laundry, and grocery shopping, but excludes care provision. I calculated the weekly hours spent by each child on housework as the dependent variable. Although concerns regarding the reliability of children's self-reported time use are inevitable, previous research has indicated that adolescents' self-reported time use is reliable (e.g., see Benin \& Edwards, 1990; Bianchi \& Robinson, 1997; Gager, Cooney, \& Call, 1999). Although issues pertaining to social desirability may have affected the children's answers, Wooldrige (2002) indicated that reliable analysis with consistent estimators was still possible because time use was the dependent variable in the regression analysis. In the absence of 
time-diary data, the CFPS provides a useful finely grained measurement of people's time use in China.

\section{Key Predictors}

Father's relative share of the parents' housework time. Data on the time spent by the parents on housework was collected and measured in the same way as that of the children. I calculated the time spent on housework per week by the mother and the father separately and then calculated the parents' relative engagement in housework as the father's share of the total time spent by the parents on housework per week. The resulting ratio, which could fall between 0 and 1, reflected the father's share of housework relative to that of the mother; 0 indicated that the mother undertook all of the housework, and 1 indicated that the father undertook all of the housework. Because less than $1 \%$ of the fathers undertook more than $90 \%$ of the parents' total housework, I replaced the top $1 \%$ to be equal to the 99 th percentile rank of 0.9 .

Family earning type. Family earning type was distinguished by parents' time spent in paid employment and their employment status. I coded a given family as a "male-breadwinner" (0) family if the mother had spent no time in paid employment or reported having been out of the labor force for more than 12 months. I coded a given family as a "dual-earner" (1) family when both parents reported having spent time in paid employment and/or being active in the labor force (employed, self-employed, or farm labor). A father's short-term unemployment indicates neither his long-term economic standing in the family nor his gender role orientation in the public sphere. Therefore, I coded as male-breadwinner families 150 cases in which the father had been out of the labor force for less than 12 months and the mother had been out of the labor force for more than 12 months. In addition, I coded as dual-earner families 56 cases in which the father had been out of the labor force for less than 12 months but the mother was active in the labor force.

Rural/urban context. The CFPS 2010 differentiated between rural (0) and urban (1) - that is, whether a given respondent resides in the jurisdiction of an urban neighborhood committee or a rural village committee according to the definitions established by the China National Statistics Bureau. Unfortunately, the limited sample size prevented me from disaggregating the sample to examine China's regional differences at the province level. 


\section{Covariates}

The first two covariates were children's gender and age. Because the time children spend on housework may be practically constrained by their educational activities, I also calculated time spent on academic studies per week, including school hours, extracurricular courses, and homework. I included a dummy for boarding school (zhudu) attendance because children at boarding school usually leave school on Fridays to spend the weekends at home, when they are likely to undertake housework. Given that high educational achievement among Chinese women is associated with less traditional gender values (Hu \& Scott, 2014), I controlled for the children's educational aspirations using a categorical variable that differentiated among "middle school," "high school or vocational high school (zhigao)," and "higher education."

I also included a series of parental and household attributes. I controlled for the time each parent spent per week on paid employment and for each parent's years of schooling. I also controlled for the square-root form of the parents' total housework hours. Siblings, especially those of the opposite gender, play a key role in molding children's gender roles. Brody and Steelman (1985) found that parents with opposite-gender children differentiated more consciously by gender between housework tasks. Girls with male siblings have been found to spend more time on housework and undertake more "feminine" tasks (Gager et al., 1999). A categorical variable was included to account for cases of "no siblings," "same-gender sibling(s)," and/or “opposite-gender sibling(s)." I also controlled for each family's socioeconomic standing in the log form of per capita annual income in Chinese yuan.

During the exploratory stage of the research, I experimented with including parents' and children's health conditions, parents' ages, relative income, hukou status (i.e., household registration type distinguishing between "agricultural" and "non-agricultural"), the household's major productive activity (farming or otherwise), household size, the presence of coresiding female and/or male grandparents, and so on.

However, because these factors neither increased the model $t$ nor affected the outcomes of the key predictors they were excluded from the analysis. The influence of these factors was probably already reflected in that of parents' relative share of housework time.

\section{Analytic Strategy}

I used ordinary least squares (OLS) regression models to estimate the time spent on housework per week by sons and daughters separately. Next, the models for sons and daughters were nested to test for potential gender difference in the regression coefficients. I 
estimated White's (1980) robust standard errors to account for households with multiple coresiding children. The models were built on several blocks of variables. Model 1 was fitted only with dummy variables for family earning type and rural-urban context. The father's relative share of the parents' housework time was added in Model 2. Covariates were included in Model 3. Model 4 tested the moderating effect of family earning type on housework-behavior modeling by including the interaction term between father's relative share of the parents' housework time and family earning type. Similarly, Model 5 tested the moderating effect of social context on housework-behavior modeling by including the interaction term between father's relative share of the parents' housework time and China's rural-urban context.

The interaction terms were fitted such that the coefficients reflected separate slopes for the influence of the parents' relative share of housework time on children's housework time in distinct family earning types and in rural and urban contexts. For example, this allowed me to retrieve separate coefficients (and thus comparable effect sizes and directions) for the influence of parents' share of housework in rural and urban contexts (Hayes, 2013, pp. 24580). I then used the lincom function in Stata to compare the between-slope differences (StataCorp, 2013, pp. 286-287). This allowed me to com- pare, for example, whether the coefficients for rural and urban areas were statistically different and thus whether the moderating effects were statistically significant. Statistical tests of the normality of residual and multicollinearity (variance inflation factor) were conducted to ensure that the use of OLS regression was appropriate. I tested the robustness of the results by fitting the OLS models to samples disaggregated by family earning type and rural-urban context. I fitted alternative Tobit and median regression models, yielding findings consistent with the OLS regression models.

\section{Results}

\section{Descriptive Statistics}

Descriptive statistics for the whole and disaggregated samples are presented in Table 1. The difference between the male-breadwinner and dual-earner families was mainly economic: The dual-earner families had a higher level of per capita annual income than the malebreadwinner families. However, rural-urban differences were observed in more than one dimension. Because of the increasingly strict enforcement of 9-year compulsory education and the particular emphasis placed on education in urban areas, children in urban China spent considerably more time on academic activities than their rural counterparts, $t_{\text {daughter }}(934)=$ 
4.93, $t_{\mathrm{son}}(965)=5.91 ; p<.001$ for both. Urban children had higher educational aspirations than their rural counterparts. Urban parents also were better educated, having longer schooling years than their rural counterparts, $t_{\text {mother }}(1,901)=18.79, t_{\text {father }}(1,901)=16.44 ; p$ $<.001$ for both. Because the one-child policy is more strictly enforced in urban than rural areas, a larger proportion of rural than urban children had siblings. An exceptionally high proportion of rural girls $(91.5 \%)$ had one or more sibling(s). This affirms the persistence of a patrilineal preference for sons, because rural parents usually attempt to have a second child if their first child is female (Greenhalgh, 2008). The results confirm previous observations that a socioeconomic gulf separates rural and urban China (e.g., Whyte, 2010). The gender differences between boys and girls were noted primarily in the educational domain; girls spent more time than boys on academic activities and had higher educational aspirations.

\section{[Insert Table 1 Here]}

Descriptive statistics on the children's and parents' work and housework-related time use are presented in Table 2. Girls were found to spend much more time than boys on housework per week $\left(M_{\text {daughter }}=4.08, M_{\text {son }}=2.91\right), t(1,901)=7.26, p<.001$. This result may in part reflect a social desirability response bias on the part of daughters and sons. Consistent with Benin and Edwards's (1990) results, children from dual-earner families were found to spend more time on housework than those from male-breadwinner families; specifically, in support of Hypothesis 2, boys but not girls in China spent considerably more time on housework in dual-earner than male-breadwinner families, $t(965)=2.91, p<.01$. This may be partially ascribed to boys' modeling of an increase in the father's relative share of the parents' housework time associated with maternal employment. In part, this may also be attributed to China's one-child policy, which makes singleton sons the only available "substitutes" for their working parents. Indeed, further bivariate analyses indicated that the influence of family earning type on children's housework time was significant only in one-child households, $t(1,460)=2.43, p<.05$, not in households with multiple children, $t(439)=0.91, p=.360$. Both boys and girls spent more time on housework in rural than in urban areas.

\section{[Insert Table 2 Here]}

Chinese mothers were found to spend nearly three times as many hours on housework than the fathers. Fathers from male-breadwinner and dual-earner families spent a similar amount of time on housework per week; however, the time spent by mothers in these two groups differed significantly. The working mothers spent 7.80 fewer hours on housework per week than the mothers from male-breadwinner families, $t(1,901)=17.06, p<.001$. This variation in mothers' housework time was also reflected in fathers' significantly greater share of the parents' housework time in dual-earner than male-breadwinner families, $\left(M_{\text {male }}=.20, M_{\text {dual }}\right.$ $=.28), t(1,901)=7.26, p<.001$. 
Although rural fathers might be expected to spend less time than urban fathers on housework, given that more traditional gender role values are held in rural areas, the results indicated the opposite $\left(M_{\text {rural }}=7.85, M_{\text {urban }}=5.39\right), t(1,901)=6.31, p<.001$. Nevertheless, rural mothers were found to spend only slightly more time than urban mothers on housework. As a result, the rural fathers' contribution to total parental housework time was significantly larger than that of their urban counterparts $\left(M_{\text {rural }}=0.27, M_{\text {urban }}=0.24\right), t(1,901)=2.61, p<.01$. The observed rural-urban differences in parents' housework time and their relative share of housework time seem contrary to sociocultural norms and may be associated with a higher total demand for housework in rural areas than in urban areas. Indeed, rural parents spent more time on housework overall than their urban counterparts, which may be attributed to the relative lack of labor-saving appliances and domestic-outsourcing options in rural areas, as Gershuny (2004) noted.

Meanwhile, a larger proportion of rural mothers (68.9\%) than urban mothers (59.6\%) participated in the labor force. Rural mothers also spent more time on paid employment than their urban counterparts $\left(M_{\text {rural }}=31.71, M_{\text {urban }}=28.52\right), t(1,901)=2.67, p<.01$, which may further increase the time spent by rural fathers on housework relative to that of their urban counterparts. Male-breadwinner fathers were found to spend less time on paid employment than their dual-earner counterparts, mainly because of the inclusion of families in which the father was temporarily out of work. When these families were excluded, the malebreadwinner and dual-earner fathers had similar paid working hours per week $\left(M_{\text {male }}=53.90\right.$, $\left.N=506 ; M_{\text {dual }}=53.29, N=1,191\right)$. Parents' time use did not differ significantly with children's gender.

\section{Regression Results}

In Table 3 I present the OLS regression estimates of the children's weekly housework time; the results for the covariates, as included in Model 3, are presented in Appendix Table A1. Fathers' relative share of the parents' housework time was significantly positively associated with sons', but not daughters', housework time, supporting Hypothesis 1 (Models 3A and 3B). Further tests indicated that the influence of fathers' relative share of the parents' housework time differed significantly between sons and daughters.

\section{[Insert Table 3 Here]}

Hypothesis 2, regarding the influence of family earning type on children's housework time, was supported by the results. On the one hand, as hypothesized, boys in dual-earner families 
spent more time on housework than those in male-breadwinner families (Model 1B). Further exploration in Model 2B indicated that the impact of family earning type on boys' housework was partially mediated by the inclusion of fathers' relative share of the parents' housework time. This suggests that maternal employment influences boys' housework in part by configuring fathers' housework behavior and through father-son housework-behavior modeling. In Model 3B, the inclusion of covariates further eliminated the influence of family earning type on boys' housework time. On the other hand, in contrast to Western findings (e.g., Benin \& Edwards, 1990; Cunningham, 2001b; Evertsson, 2006), family earning type was not significantly associated with girls' housework time in China. This could be because the influences of housework-behavior modeling and an increased demand for substitution on girls offset each other when working mothers do a smaller share of the parents' housework.

\section{[Insert Figure 1 Here]}

Models 4 and 5 tested the moderating effects of family earning type and China's rural-urban context on housework-behavior modeling. Depicting the moderation effects specified in Hypotheses 3 and 4, Figure 1 illustrates the predicted influences of the parents' relative share of housework time on sons' and daughters' housework time by family earning type (top panels) and rural-urban context (lower panels), respectively. I first present and discuss separate coefficients for father's share of housework in distinct contexts, and then I address the between-coefficient differences in terms of moderating effects.

Model 4B and Figure 1 (top right panel) clearly show that in both male-breadwinner and dual-earner families sons' housework time increased as their fathers' share of housework increased. Although the coefficient for fathers' share of housework time on boys' housework time was slightly larger in male-breadwinner $(B=2.67, p<.01)$ than dual-earner families $(B$ $=1.09, p<.10$ ), further tests indicated that the difference between the two coefficients was not statistically significant, $F(1,949)=2.44$, ns. Therefore, Hypothesis 3 , which posited that family earning type moderates boys' housework-behavior modeling, was not sup- ported. However, consistent with our prediction for girls, the parents' relative share of house- work did not significantly affect daughters' housework time in either male-breadwinner or dualearner families.

The results support Hypotheses 4A and 4B, which stated that China's rural and urban contexts moderate the effect of housework-behavior modeling differently for boys and girls. Confirming Hypothesis 4A, the results indicated that daughters' housework-behavior modeling (of a decrease in their mothers' relative share of the parents' housework time) is stronger in urban $(B=-0.92)$ than in rural $(B=0.76)$ areas, between-slope difference: $F(1$, $874)=2.95, p<.10$. In rural areas, as depicted in Figure 1 (solid line in lower left panel), daughters' housework time was found to increase as fathers contributed a greater relative 
share and mothers contributed a smaller relative share to the parents' total housework time. In contrast, in urban areas (dashed line in lower left panel of Figure 1), daughters were found to spend less time on housework as their mothers contributed a smaller relative share and their fathers contributed a greater relative share to the parents' total housework time. Therefore, in part, the results for girls support Andersson et al.'s (2006) theory that parental housework behavior that is congruent with normative expectations encourages daughters' positive housework-behavior modeling, whereas incongruence deters behavior modeling. In addition, the results for rural-urban moderation on girls' housework-behavior modeling could be partially ascribed to a greater array of domestic-outsourcing options and labor-saving tools in urban than rural China (Evans \& Strauss, 2011), which allows urban, but not rural, girls greater discretion to model than substitute for their mothers' decreasing share of housework time.

The results are also consistent with Hypothesis 4B (see lower right panel of Figure 1), indicating that the association between fathers' relative share of the parents' housework time and sons' housework time was slightly stronger in more traditional rural $(B=1.89, p<.01)$ than urban areas $(B=1.15, p<.10)$. This is consistent with Crouter et al.'s (1993) and Cunningham's (2001b) conjecture that parents' housework behavior plays a greater role in reducing the link between gender and housework in more traditional social settings. This also lends support to Crouter et al.'s contention that because housework norms are less defined for boys than for girls then boys, more than girls, take cues from their parents in learning to do housework. The results of complex interplays among China's rural-urban context, children's gender, and housework-behavior modeling underpin distinct mechanisms of intergenerational gender role socialization for boys and girls.

\section{Discussion}

Children's gender role socialization is key to a sound understanding of the reproduction of gender inequalities in the domestic sphere. Previous researchers have identified intergenerational behavior modeling as a key mechanism of gender role reproduction (e.g., Cunningham, 2001b; Evertsson, 2006; Greenstein, 1996) and have emphasized the importance of examining gender role socialization in its sociocultural context (Bronfenbrenner, 1989; McHale et al., 2003). However, this study bridged an important gap in the existing scholarship in that I explicitly tested the contextual variation in behavior modeling. This was made possible by the comparative lens of China's distinctive rural and urban contexts, which, although they share a homogeneous sociocultural origin, have diverged markedly in aspects such as normative gender role values and alternative domestic 
options. This analysis of data from the 2010 CFPS highlights similarities and differences between China and Western societies. Whereas the similarities facilitate the development of generalization about gender role socialization processes, the differences allow us to identify how intergenerational processes within the family are embedded in and configured by social contexts.

Consistent with research conducted in Western societies (Álvarez \& Miles-Touya, 2012; Cunningham, 2001b; Evertsson, 2006), in this study parents' relative share of housework time was significantly associated with the time spent on housework by their sons, but not their daughters, in China. Although social learning theory, which is associated with social psychologists such as Bandura and Walters (1963), indicates that behavior modeling can affect boys and girls equally, researchers in both Western and Chinese contexts have provided abundant evidence that daughters rather than sons usually substitute for a decrease in their mothers' relative share of housework. As a result, substitution and houseworkbehavior modeling could offset each other's influence on girls (e.g., Benin \& Edwards, 1990; Cunningham, 2001b; Evans, 2008; Goldscheider \& Waite, 1991; Gupta, 2006; Lundburg, 2005). Nevertheless, in order to understand further the interplay between substitution and housework-behavior modeling, future research should collect and analyze data on how, with whom, and in what ways male and female children spend their time.

Whereas research conducted in Western societies has consistently emphasized the importance of maternal employment in de-traditionalizing girls' housework behavior (Benin \& Edwards, 1990; Gupta, 2006; McHale et al., 2003), this has not been the case for Chinese girls. For boys, further to Gupta's (2006) finding of a long-term effect of early maternal employment on adult men's gender roles, this study revealed a positive association between maternal employment and Chinese sons' housework time from childhood onwards. Furthermore, given that the parents' relative share of housework time mediated the association between family earning type and sons' housework time, the results suggest that maternal employment may affect boys' housework behavior indirectly by configuring fathers' housework behavior. The moderating effect of family earning type on housework-behavior modeling observed in Western societies (Álvarez \& Miles-Touya, 2012; Crouter et al., 1987; McHale et al., 1990) is largely unsupported in the Chinese context.

Why does family earning type affect children's housework behavior differently in China? Western researchers have ascribed the influence of family earning type on children's housework behavior (net of parents' time availability) to the theory that maternal employment increases women's relative resources, reduces their involvement in housework, and erodes traditional domestic gender role values (see Raley \& Bianchi, 2006, for a comprehensive review). In China, the lack of association between family earning type and 
daughters' housework time indicates that female employment has not necessarily led to daughters' more egalitarian domestic gender role values. Therefore, the results may suggest the limited reach of China's externally enforced socialist programs in promulgating gender equality at home. Alternatively, if maternal employment does lead to more egalitarian domestic gender role values among women, as Hu and Scott (2014) reported, such ideational change certainly has not been equally reflected in girls' housework behavior. This implies that future studies should collect data on both people's behavior and their subjective ideations in order to better understand the factors that impede Chinese females from translating egalitarian domestic gender role values into behavior.

Many of the insights gained from this research would not have been possible without comparing China's rural-urban differences. The moderation effect of China's rural-urban context on housework-behavior modeling suggests that boys and girls relate to parental behavior and social context to varying degrees and in distinct ways. This finding underpins how boys and girls learn to "do gender" differently. On the one hand, there is room for optimism in that parents' housework and employment behavior seem to erode existing gender norms in affecting sons' housework time. On the other hand, the congruence between parents' equal division of housework and egalitarian gender role values in urban rather than rural China seems to encourage daughters' housework-behavior modeling, as Andersson and colleagues (2006) argued. This suggests that, without changes in wider gender norms, the influence of parents' egalitarian housework behavior is hindered in promulgating gender equality.

In the meantime, children's, and in particular girls', housework behavior is subject to practical constraints. In part, the results may also suggest that girls could compensate for rather than model their mothers' decreased share of the parents' housework time in rural China, where options of domestic outsourcing and labor-saving appliances are limited. Conversely, in urban China, where such alternative substitution options are readily available, girls may have the discretion to model rather than compensate for their mothers' decreased share of the parents' housework time. The affordability of alternative domestic options for individual families helps reduce girls' (but not boys') housework time (as reflected in the results for per capita annual income in Appendix Table A1). However, these results may also reflect the macro-level difference in the availability of resources such as domestic outsourcing and labor-saving appliances between rural and urban China. As such, without wider social institutional and material support, Chinese mothers' achievement of egalitarian domestic gender roles could come at the cost of their daughters' sinking deeper into domesticity, insofar as domestic burden is off-loaded onto girls as "natural substitutes" for their mothers. 
One weakness of the current study is that, because of data limitations, I used an individual's rural-urban residence to distinguish gender norms and alternative substitution options, which are attributed to the contextual level. Thus, the regression models did not incorporate any direct measures of rural-urban characteristics. In future studies it will be important to include measures that tap gender values and substitution options at both an individual and a community level in order to disentangle how normative contextual values and substitution opportunities impact on domestic gender roles.

Furthermore, the study of gender socialization as an ongoing, long-term, and socially embedded process ideally requires longitudinal data. As is inevitable with cross-sectional data, causal inference is problematic, and the results reported above indicate association rather than causality. In addition, intergenerational relations may be a two-way process (Raley \& Bianchi, 2006); children's agency is also likely to be important in shaping their own housework behavior. Although I included children's subjective educational aspirations as a covariate, the data included no measures of children's views regarding appropriate gender roles. Despite these limitations, this research provides a baseline for future exploration and demonstrates the insights that can be gained from studying children's gender role socialization in its sociocultural context, in particular in non-Western developing countries. 


\section{References}

Álvarez, B., \& Miles-Touya, D. (2012). Exploring the relationship between parents' and children's housework time in Spain. Review of Economics of the Household, 10, 299318. doi:10.1007/s11150-011-9135-4

Andersson, G., Hank, K., Rønsen, M., \& Vikat, A. (2006). Gendering family composition: Sex preferences for children and childbearing behavior in the Nordic countries. Demography, 43, 255-267. doi:10.1353/dem.2006.0010

Bandura, A., \& Walters, R. H. (1963). Social learning and personality development. New York: Holt, Rinehart \& Winston.

Becker, G. S. (1991). A treatise on the family. Cambridge, MA: Harvard University Press.

Benin, M. H., \& Edwards, D. A. (1990). Adolescents' chores: The difference between and single-earner families. Journal of Marriage and the Family, 52, 361-373. doi:10.2307/ 353032

Bianchi, S. M., \& Robinson, J. (1997). What did you do today? Children's use of time, family composition, and the acquisition of social capital. Journal of Marriage and the Family, 59, 332-344. doi:10.2307/353474

Bittman, M., England, P., Sayer, L., Folbre, N., \& Matheson, G. (2003). When does gender trump money? Bargaining and time in household work. American Journal of Sociology, 109, 186-214. doi:10.1086/378341

Blair, S. L. (1992). The sex-typing of children's household labor: Parental influence on daughters' and sons' housework. Youth \& Society, 24, 178-203.

Brody, C. J., \& Steelman, L. C. (1985). Sibling structure and parental sex-typing of children's household tasks. Journal of Marriage and the Family, 47, 265-273. doi: $10.2307 / 352127$

Bronfenbrenner, U. (1989). Ecological systems theory. In R. Vasta (Ed.), Six theories of child development: Revised formulations and current issues (pp. 187-249). London: JAI Press.

Coltrane, S. (2000). Research on household labor: Modeling and measuring the social embeddedness of routine family work. Journal of Marriage and the Family, 62, 1208 1233. doi:10.1111/j. 1741-3737.2000.01208.x

Crouter, A. C., McHale, S. M., \& Bartko, W. T. (1993). Gender as an organizing feature in parent-child relationships. Journal of Social Issues, 49, 161-174. doi:10.1111/j.15404560. 1993.tb01174.x 
Crouter, A. C., Perry-Jenkins, M., Huston, T. L., \& McHale, S. M. (1987). Processes underlying father involvement in dual-earner and single-earner families. Developmental Psychology, 23, 431-440. doi:10.1037/0012-1649.23.3.431

Cunningham, M. (2001a). The influence of parental attitudes and behaviors on children's attitudes toward gender and household labor in early adulthood. Journal of Marriage and Family, 63, 111-122. doi:10.1111/j.1741-3737.2001.00111.x

Cunningham, M. (2001b). Parental influences on the gendered division of housework. American Sociological Review, 66, 184-203. doi:10.2307/2657414

Evans, H. (2008). The subject of gender: Daughters and mothers in urban China. Lanham, MD: Rowman \& Little Field.

Evans, H., \& Strauss, J. C. (2011). Gender influx: Agency and its limits in contemporary China. Cambridge, UK: Cambridge University Press.

Evertsson, M. (2006). The reproduction of gender: Housework and attitudes towards gender equality in the home among Swedish boys and girls. The British Journal of Sociology, 57, 415-436. doi:10.1111/j.1468-4446.2006.00118.x

Fong, V. L. (2002). China's one-child policy and the empowerment of urban daughters. American Anthropologist, 104, 1098-1109. doi:10.1525/aa.2002.104.4.1098

Gager, C. T., Cooney, T. M., \& Call, K. T. (1999). The effects of family characteristics and time use on teenagers' household labor. Journal of Marriage and the Family, 61, 982994. doi: $10.2307 / 354018$

Gershuny, J. (2003). Changing times: Work and leisure in postindustrial society. New York: Oxford University Press.

Gershuny, J. (2004). Domestic equipment does not increase domestic work: A response to Bittman, Rice and Wajcman. The British Journal of Sociology, 55, 425-431. doi:10.1111/j.1468-4446. 2004.00027.x

Goffman, E. (1977). The arrangement between the sexes. Theory and Society, 4, 301-331. doi:10.1007/BF00206983

Goldscheider, F. K., \& Waite, L. J. (1991). New families, no families? Berkeley: University of California Press.

Greenhalgh, S. (2008). Just one child: Science and policy in Deng's China. Berkeley: University of California Press.

Greenstein, T. N. (1996). Husbands' participation in domestic labor: Interactive effects of wives' and husbands' gender ideologies. Journal of Marriage and the Family, 58, 585595. doi:10.2307/ 353719 
Grusec, J. E., \& Hastings, P. D. (2008). Handbook of socialization: Theory and research. New York: Guilford Press.

Gupta, S. (2006). The consequences of maternal employment during men's childhood for their adult housework performance. Gender \& Society, 20, 60-86. doi: $10.1177 / 0891243205282554$

Hayes, A. F. (2013). Introduction to mediation, moderation, and conditional process analysis: A regression-based approach. New York: Guilford Press.

Hu, Y., \& Scott, J. (2014). Family and gender values in China: Generational, geographic and gender differences. Journal of Family Issues. Advance online publication. doi:10.1177/0192513X14528710

Lundberg, S. (2005). Sons, daughters, and parental behavior. Oxford Review of Economic Policy, 21, 340-356. doi:10.1093/oxrep/gri020

Manke, B., Seery, B. L., Crouter, A. C., \& McHale, S. M. (1994). The three corners of domestic labor: Mothers', fathers', and children's weekday and weekend housework. Journal of Marriage and the Family, 56, 657-668. doi:10.2307/352876

McHale, S. M., Bartko, W. T., Crouter, A. C., \& Perry-Jenkins, M. (1990). Children's housework and psychosocial functioning: The mediating effects of Parents' sex-role behaviors and attitudes. Child Development, 61, 1413-1426. doi:10.1111/j.14678624.1990.tb02871.x

McHale, S. M., Crouter, A. C., \& Whiteman, S. D. (2003). The family contexts of gender development in childhood and adolescence. Social Development, 12, 125-148. doi:10.1111/1467-9507.00225

Organisation for Economic Cooperation and Development. (2011). Education at a glance in 2011: Country note: China. Paris: Author. doi:10.1787/eag_highlights-2011-en

Organisation for Economic Co-operation and Development. (2015). Employment and labor markets: Key tables from OECD. Paris: Author. doi:10.1787/20752342

Raley, S., \& Bianchi, S. (2006). Sons, daughters, and family processes: Does gender of children matter? Annual Review of Sociology, 42, 401-421.

doi:10.1146/annurev.soc.32.061604.123106

StataCorp. (2013). Stata: Release 13 [Computer software]. College Station, TX: StataCorp LP.

Tam, S. M., Wong, W. C. A., \& Wang, D. (2014). Gender and family in East Asia. New York: Routledge. West, C., \& Zimmerman, D. H. (1987). Doing gender. Gender \& Society, 1, 125-151. doi:10.1177/0891243287001002002 
White, H. (1980). A heteroskedasticity-consistent covariance matrix estimator and a direct test for heteroskedasticity. Econometrica, 48, 817-838. doi:10.2307/1912934

Whyte, M. K. (1978). The status of women in pre-industrial societies. Princeton, NJ: Princeton University Press.

Whyte, M. K. (2010). One country, two societies: Rural-urban inequality in contemporary China. Cambridge, MA: Harvard University Press.

Wooldridge, J. M. (2002). Econometric analysis of cross section and panel data. Cambridge, MA: MIT Press.

Yan, Y. (2009). The individualization of Chinese society. New York: Bloomsbury Academic.

Yu, J. (2014). Gender ideology, modernization, and women's housework time in China. Chinese Journal of Sociology, 34, 166-192.

Zuo, J., \& Bian, Y. (2001). Gendered resources, division of housework, and perceived fairness - A case in urban China. Journal of Marriage and Family, 63, 1122-1133. doi:10.1111/j.1741-3737.2001.01122.x 


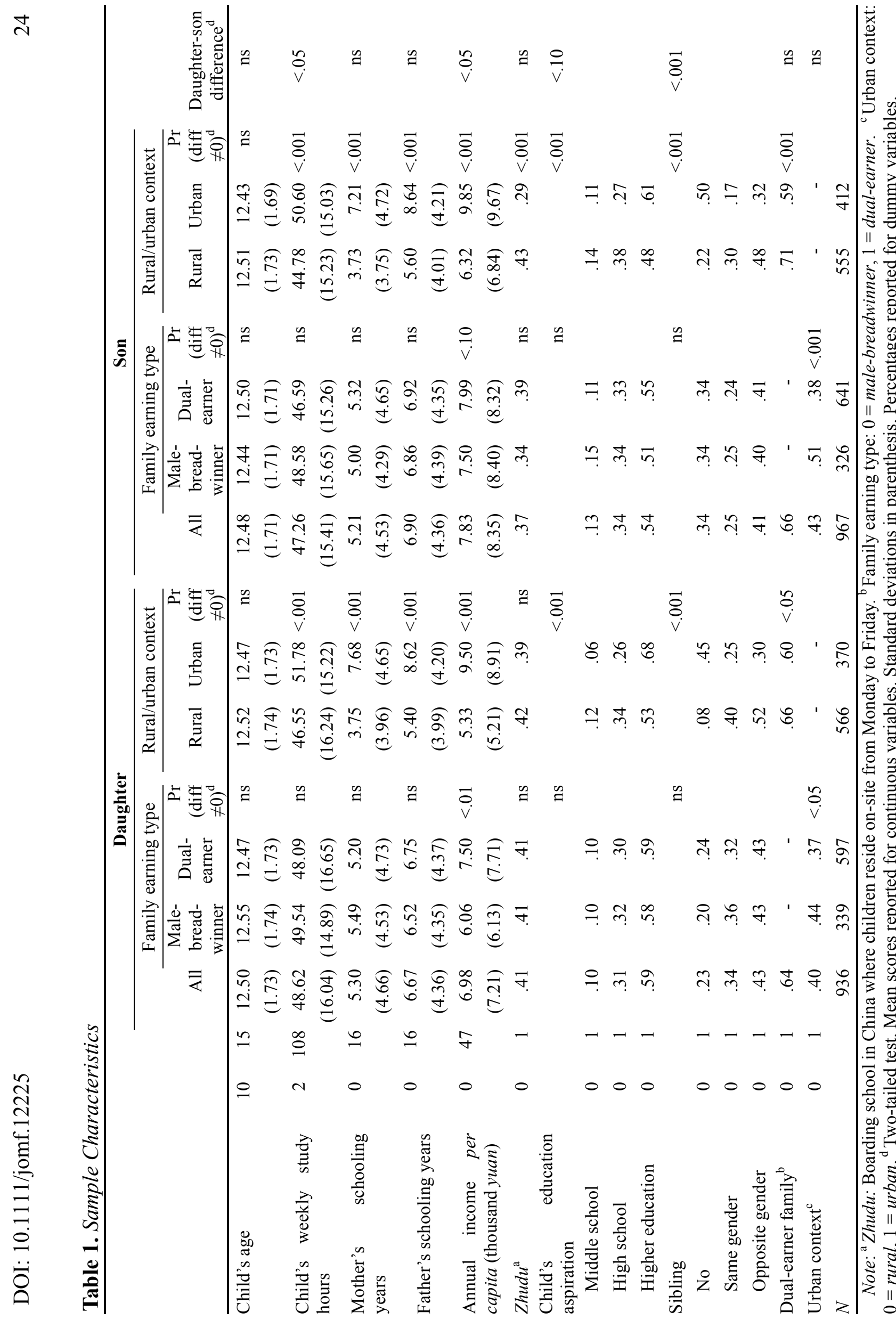




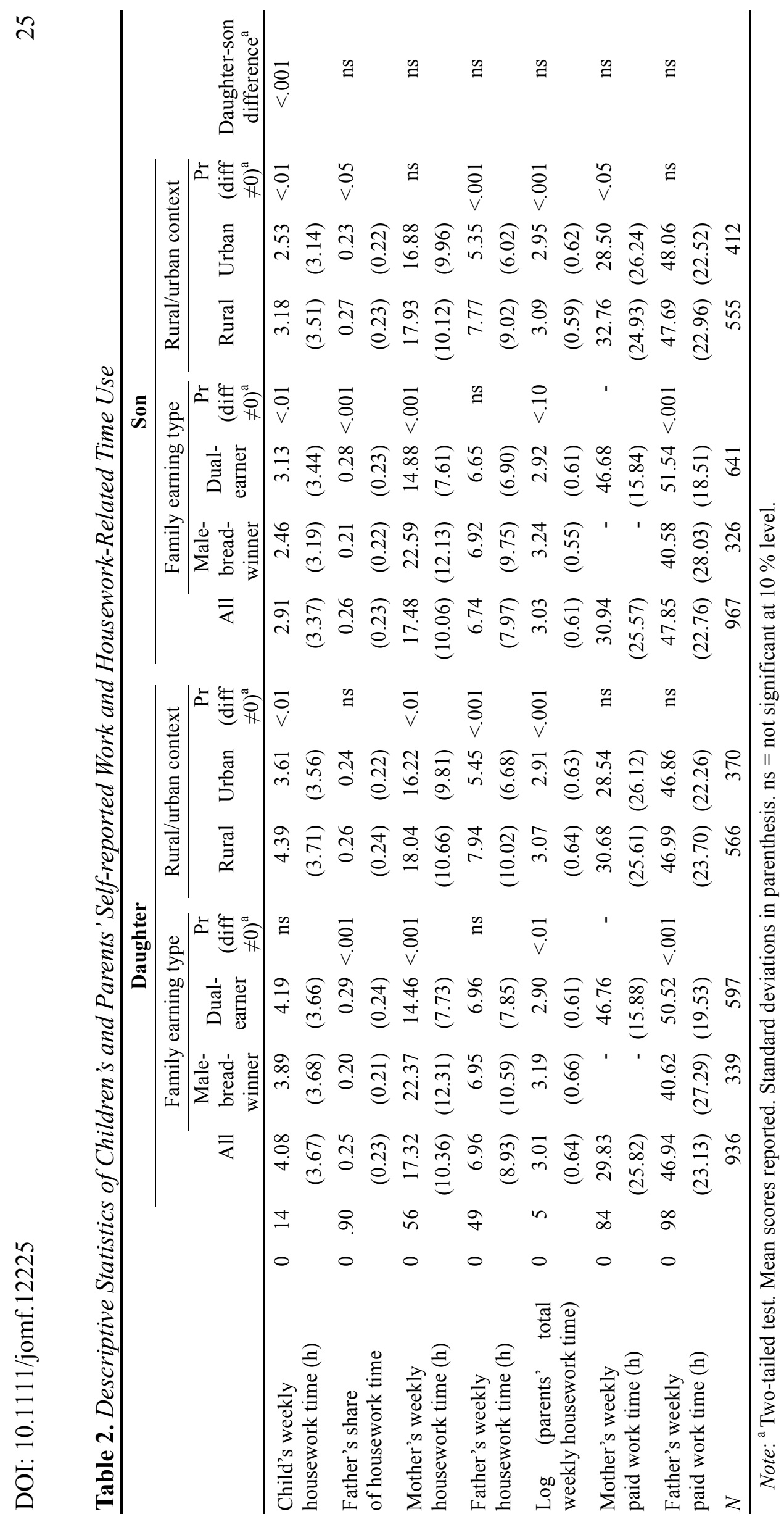

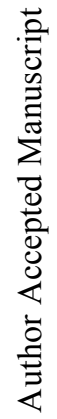




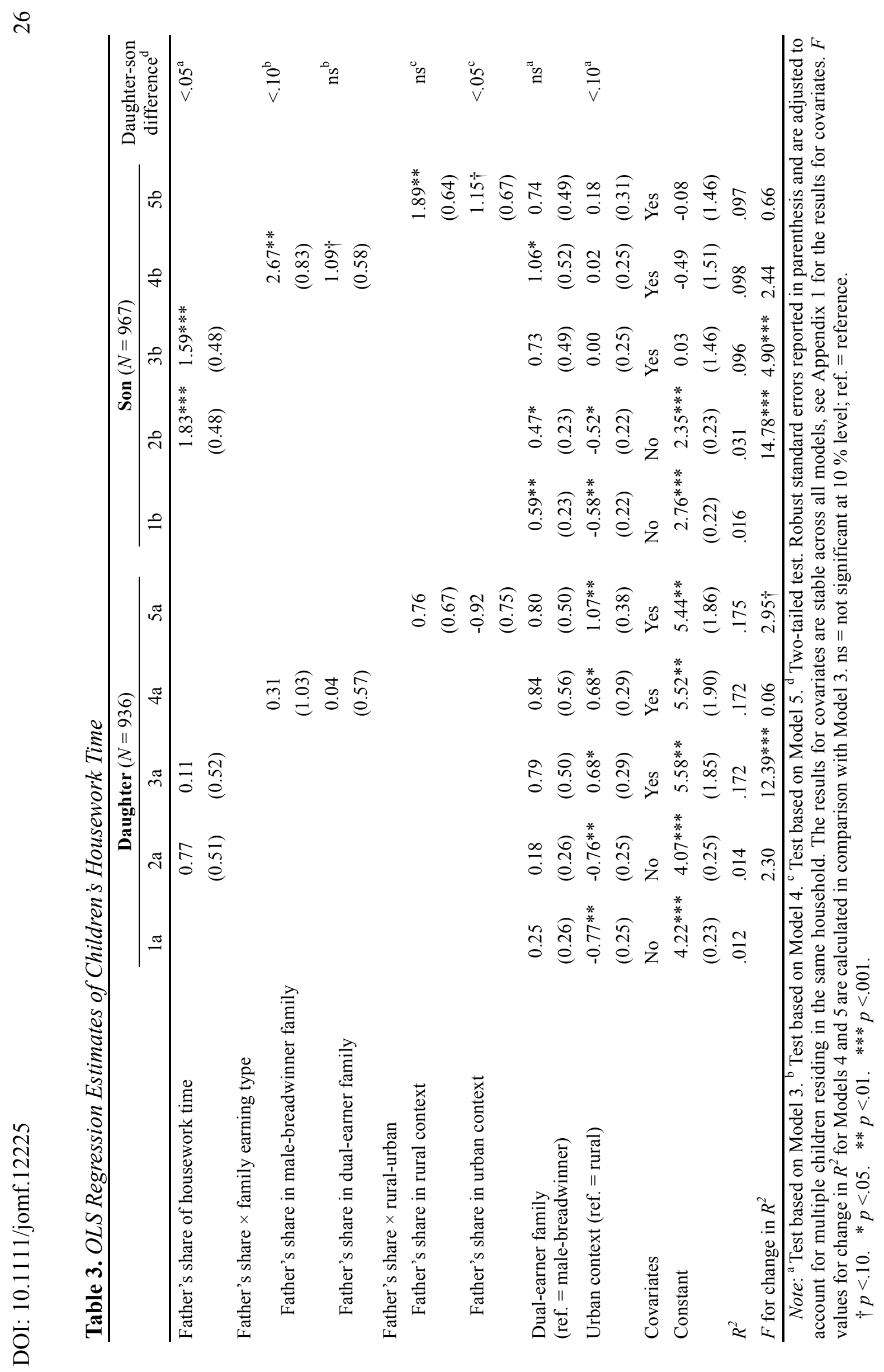

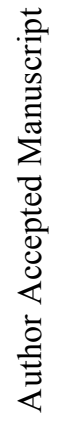


FIGURE 1. LINEAR PREDICTIONS OF A DAUGHTER'S AND SON'S WEEKLY HOUSEWORK TIME BY THE FATHER'S SHARE OF HOUSEWORK TIME, BY THE FAMILY EARNING TYPE AND RURAL/URBAN CONTEXT.
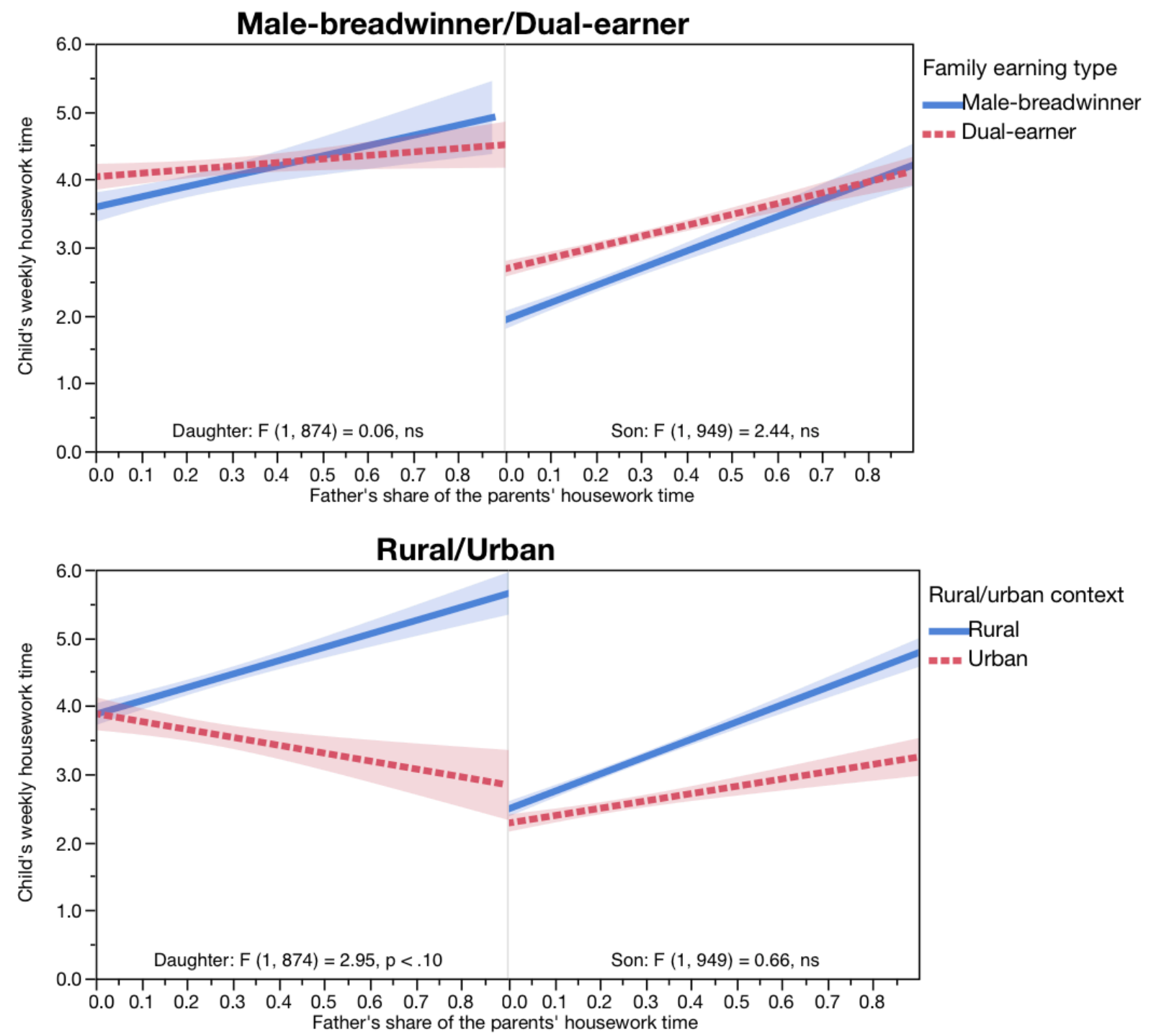

Note: Predicted values are computed from Models $4 \mathrm{a}$ and $5 \mathrm{a}, 4 \mathrm{~b}$ and $5 \mathrm{~b}$ in Table 3 , with all categorical variables set as the reference category and all continuous variables set at the mean level of the whole sample. ns $=$ not significant at $10 \%$ level. Bands indicate $95 \%$ confidence intervals. 
Appendix 1. OLS Regression Results for Covariates, by Children's Gender

\begin{tabular}{|c|c|c|c|c|c|}
\hline & \multicolumn{2}{|c|}{ Daughter $(N=936)$} & \multicolumn{2}{|c|}{ Son $(N=967)$} & \multirow{2}{*}{$\begin{array}{c}\text { Daughter-son } \\
\text { difference }^{b}\end{array}$} \\
\hline & $B$ & $(S E)$ & $B$ & $(S E)$ & \\
\hline & \multicolumn{5}{|c|}{ (Continues from Model $3 a$ and $3 b$ in Table 3) } \\
\hline Sqrt (parents' total weekly housework time) & $0.32 * * *$ & $(0.09)$ & \multicolumn{2}{|c|}{$0.31 * * *(0.08)$} & ns \\
\hline Mother's weekly paid work time & -0.00 & $(0.01)$ & 0.00 & $(0.01)$ & $\mathrm{ns}$ \\
\hline Father's weekly paid work time & 0.00 & $(0.01)$ & 0.01 & $(0.00)$ & $\mathrm{ns}$ \\
\hline Child's age & 0.11 & $(0.07)$ & $0.14 *$ & $(0.07)$ & $\mathrm{ns}$ \\
\hline Child's weekly study hours & $-0.03 * * *$ & $(0.01)$ & -0.01 & $(0.01)$ & ns \\
\hline $\begin{array}{l}Z h u d u^{\mathrm{a}} \\
\text { Child's education aspiration } \\
\text { (ref. = middle school) }\end{array}$ & $-1.16^{* * *}$ & $(0.25)$ & \multicolumn{2}{|c|}{$-0.92 * * *(0.24)$} & ns \\
\hline High school & -0.49 & $(0.42)$ & 0.34 & $(0.37)$ & $\mathrm{ns}$ \\
\hline Higher education & $-0.96^{*}$ & $(0.42)$ & 0.44 & $(0.36)$ & $<.01$ \\
\hline \multicolumn{6}{|l|}{ Sibling (ref. = no) } \\
\hline Same-gender & $1.15 * *$ & $(0.36)$ & 0.36 & $(0.31)$ & $<.10$ \\
\hline Opposite-gender & $1.05 * *$ & $(0.37)$ & $0.55^{*}$ & $(0.27)$ & ns \\
\hline Mother's schooling years & -0.04 & $(0.03)$ & 0.01 & $(0.03)$ & $\mathrm{ns}$ \\
\hline Father's schooling years & $-0.09 * *$ & $(0.03)$ & $-0.09 * *$ & $(0.03)$ & $\mathrm{ns}$ \\
\hline Log (annual income per capita) & $-0.32 *$ & $(0.15)$ & -0.11 & $(0.11)$ & ns \\
\hline Constant & $5.58 * *$ & $(1.85)$ & 0.03 & $(1.46)$ & \\
\hline$R^{2}$ & .172 & & .096 & & \\
\hline
\end{tabular}

Note: ${ }^{a}$ Boarding school in China where children usually reside in school from Monday morning to Friday afternoon. ${ }^{b}$ Two-tailed tests. Standard errors reported in parenthesis and are adjusted to account for multiple children residing in the same household. The results for covariates are based on Model 3 in Table 3, and the coefficients are stable across all models reported in Table $3 . \mathrm{ns}=$ not significant at $10 \%$ level; ref. $=$ reference.

$* p<.05$. ** $p<.01 . \quad * * * p<.001$. 